\title{
Severe head injury and the risk of early death
}

G R Boto, P A Gómez, J De La Cruz, R D Lobato

See end of article for authors' affiliations

Correspondence to G R Boto, Avda Doctor García Tapia, 159 Porta D Ático B, 28030 Madrid Spain;

grboto@yahoo.es

Received

23 December 2005

Revised version received

11 April 2006

Accepted 18 May 2006

Published Online First

1 June 2006
S evere head injury (SHI) remains the main cause of mortality and morbidity in people aged $\leqslant 40$ years in all westernised nations. The death rates of SHI nowadays range from $30 \%$ to $50 \%$, figures very similar to those reported 30 years ago, despite efforts to better this. To improve the outcome of SHI, many phase III clinical trials have been developed in the past decade but, unfortunately, none has shown efficacy, in contrast with the success achieved in animal laboratory studies. ${ }^{1}$ One of the reasons for this failure could rest on the inclusion of patients with high risk of death. Our study aimed to develop a prognostic model for identification of patients with high risk of death in order to exclude them from future clinical trials for SHI.

\section{METHODS}

\section{Study setting}

We conducted a retrospective, population-based study at the Hospital 12 de Octubre, Madrid, Spain, from 1 January 1987 to 31 August 1999. In this period, the Department of Neurosurgery at this hospital attended to a total of 1009 consecutive patients with non-missile SHI and age $>14$ years, in whom at least one computed tomography scan was carried out at any time after their admission. Of these patients, 114 were excluded because the computed tomography scan was carried out after the first $6 \mathrm{~h}$ of injury. Therefore, we included a total of 895 patients. Cases detected from I January 1987 to 31 December 1995 (652 patients) were used to derive the prognostic model, and those gleaned from 1 January 1996 to 31 August 1999 (the remaining 243 patients) were used to validate it.

\section{Definitions}

Head injury was defined as severe when the patient scored $\leqslant 8$ points on the Glasgow Coma Scale (GCS) ${ }^{2}$ after nonsurgical resuscitation, within the first $6 \mathrm{~h}$ of injury.

Total GCS score and motor response were assessed after non-surgical resuscitation through the first $6 \mathrm{~h}$ after trauma, provided the patients were not sedated or pharmacologically paralysed. We classified them into two categories: high (scores of 6,7 or 8 ) and low (scores of 3, 4 or 5) total GCS score; likewise, high ( 4 or 5 points on motor GCS) and low ( 1 (flaccidity), 2 (decerebration) or 3 points) motor GCS score.

Pupils were classified after non-surgical resuscitation within the first $6 \mathrm{~h}$ after trauma as unknown (assessment inaccurate); not "pathological" both pupils equal and reactive or asymmetric (difference $\geqslant 2 \mathrm{~mm}$ ) or non-reactive pupils but non-mydriatic (mydriasis was assessed when the pupillary size was $>4 \mathrm{~mm}$ )); non-reactive unilateral mydriasis; and non-reactive bilateral mydriasis.

Neurological worsening was defined as the spontaneous decrease in motor GCS score of $\geqslant 2$ points during the first $6 \mathrm{~h}$ after injury, and in those patients who were sedated or pharmacologically paralysed as the development of nonreactive unilateral or bilateral mydriasis or any major change on the control computed tomography scan that warranted immediate medical or surgical intervention. ${ }^{3}$ In these patients, we considered the GCS score and pupillary category displayed after such neurological worsening as final.

Shock and hypoxia were defined by any episode recorded (including cardiorespiratory arrest) of systolic blood pressure $\leqslant 90 \mathrm{~mm} \mathrm{Hg}$ or arterial oxygen saturation $\leqslant 90 \%$ within the first $6 \mathrm{~h}$ after trauma.

Findings on computed tomography scan were classified according to the Traumatic Coma Data Bank. ${ }^{4}$ In those patients in whom changes could be outlined on the control computed tomography scan obtained during the first $6 \mathrm{~h}$ after injury, the final Traumatic Coma Data Bank category assessed was the one associated with the greatest overall mortality, in the following order from the worst to the best outcome: traumatic lesion type VI (non-evacuated mass), type IV (diffuse injury IV—shift), type III (diffuse injury IIIswelling), type V (evacuated mass), type II (diffuse injury II) and type I (diffuse injury I-no visible pathology). ${ }^{5}$

Abbreviations: GCS, Glasgow Coma Scale; ROC, receiver-operator characteristic; $\mathrm{SHI}$, severe head injury 
Table 1 Prognostic factors of early death after severe head injury: summary of univariate analysis for patients in the derivation set

\begin{tabular}{|c|c|c|c|c|}
\hline \multirow[b]{2}{*}{ Variable } & \multicolumn{2}{|c|}{ No $(\%)$ of patients ( $n=652)$} & \multirow[b]{2}{*}{ OR $(95 \% \mathrm{Cl})$} & \multirow[b]{2}{*}{ p Value } \\
\hline & $\begin{array}{l}\text { Dead within } \\
\text { the first } 48 \mathrm{~h} \\
(\mathrm{n}=114)\end{array}$ & $\begin{array}{l}\text { Remaining } \\
\text { patients } \\
(n=538)\end{array}$ & & \\
\hline \multicolumn{5}{|l|}{ Age (years) } \\
\hline$\geqslant 65$ & 19 (34.5) & $36(65.5)$ & 3.12 (1.54 to 6.32$)$ & $<0.001$ \\
\hline $55-64$ & $7(13.2)$ & $46(86.8)$ & $0.90(0.34$ to 2.28$)$ & 0.81 \\
\hline $45-54$ & $9(14.5)$ & $53(85.5)$ & 1.01 (0.42 to 2.33$)$ & 0.99 \\
\hline $35-44$ & $15(20.0)$ & $60(80.0)$ & $1.48(0.72$ to 3.01$)$ & 0.25 \\
\hline $25-34$ & $27(17.9)$ & $124(82.1)$ & $1.29(0.72$ to 2.29$)$ & 0.36 \\
\hline $15-24^{*}$ & 37 (14.5) & $219(85.5)$ & 1 & - \\
\hline \multicolumn{5}{|l|}{ Total GCS score } \\
\hline 3 & $62(64.6)$ & $34(35.4)$ & 67.5 (14.9 to 424$)$ & $<0.001$ \\
\hline 4 & $31(26.7)$ & $85(73.3)$ & 13.5 (2.99 to 84.5$)$ & $<0.001$ \\
\hline 5 & $13(12.0)$ & $95(88.0)$ & 5.06 (1.04 to 33.6$)$ & 0.02 \\
\hline 6 & $3(2.7)$ & $110(97.3)$ & 1.01 (0.13 to 8.87 ) & $1.00 \dagger$ \\
\hline 7 & $3(2.1)$ & $140(97.9)$ & $0.79(0.10$ to 6.95$)$ & $1.00 \dagger$ \\
\hline $8^{*}$ & $2(2.6)$ & $74(97.4)$ & 1 & - \\
\hline Low & $106(33.1)$ & $214(66.9)$ & $20.1(9.24$ to 45.4$)$ & $<0.001$ \\
\hline High* & $8(2.4)$ & $324(97.6)$ & 1 & - \\
\hline \multicolumn{5}{|l|}{ Motor GCS score } \\
\hline 1 & $62(64.6)$ & $34(35.4)$ & $74.0(26.1$ to 227$)$ & $<0.001$ \\
\hline 2 & $31(26.7)$ & 85 (73.3) & $14.8(5.25$ to 45.0$)$ & $<0.001$ \\
\hline 3 & $13(11.8)$ & $97(88.2)$ & $5.44(1.74$ to 18.1$)$ & $<0.001$ \\
\hline 4 & $3(2.5)$ & $119(97.5)$ & $1.02(0.19$ to 5.02$)$ & $1.00+$ \\
\hline $5^{*}$ & $5(2.4)$ & $203(97.6)$ & 1 & - \\
\hline \multicolumn{5}{|l|}{ Motor GCS score } \\
\hline Low & $106(32.9)$ & $216(67.1)$ & $19.8(9.10$ to 44.7$)$ & $<0.001$ \\
\hline High* & $8(2.4)$ & $322(97.6)$ & 1 & - \\
\hline Pupils & & & & \\
\hline Non-reactive bilateral myc & is $80(62.0)$ & $49(38.0)$ & 37.8 (18.4 to 79.3$)$ & $<0.001$ \\
\hline Non-reactive unilateral & & & $2.44(1.11$ to 5.44$)$ & \\
\hline mydriasis & $20(9.5)$ & $190(90.5)$ & & 0.02 \\
\hline Unknown & $2(8.7)$ & $21(91.3)$ & $2.21(0.00$ to 11.5$)$ & $0.27 \dagger$ \\
\hline Not "pathological"** & $12(4.1)$ & $278(95.9)$ & 1 & - \\
\hline Seizure & & & & \\
\hline Yes & $2(4.5)$ & $42(95.5)$ & $0.21(0.03$ to 0.91$)$ & 0.02 \\
\hline $\mathrm{No}^{*}$ & $112(18.4)$ & $496(81.6)$ & 1 & - \\
\hline Shock & & & & \\
\hline Yes & $82(33.3)$ & $164(66.7)$ & 5.84 (3.65 to 9.38 ) & $<0.001$ \\
\hline $\mathrm{No}^{*}$ & $32(7.9)$ & $374(92.1)$ & 1 & - \\
\hline Hypoxia & & & & \\
\hline Yes & $59(28.0)$ & $152(72.0)$ & $2.72(1.77$ to 4.20$)$ & $<0.001$ \\
\hline No* & 55 (12.5) & $386(87.5)$ & 1 & - \\
\hline Urgent extracranial surgery & & & & \\
\hline Yes & $14(35.0)$ & $26(65.0)$ & 2.76 (1.32 to 5.72 ) & 0.003 \\
\hline $\mathrm{No}^{*}$ & $100(16.3)$ & $512(83.7)$ & 1 & - \\
\hline Anaemia & & & & \\
\hline Unknown & $29(60.4)$ & $19(39.6)$ & $19.2(7.66$ to 49.0$)$ & $<0.001$ \\
\hline Yes & $74(16.3)$ & $381(83.7)$ & $2.44(1.21$ to 5.01$)$ & 0.007 \\
\hline No* & $11(7.4)$ & $138(92.6)$ & 1 & - \\
\hline Coagulopathy & & & & \\
\hline Unknown & $28(57.1)$ & $21(42.9)$ & 34.4 (11.8 to 106$)$ & $<0.001$ \\
\hline Yes & $80(18.1)$ & $362(81.9)$ & 5.71 (2.34 to 14.9$)$ & $<0.001$ \\
\hline $\mathrm{No}^{*}$ & $6(3.7)$ & $155(96.3)$ & 1 & - \\
\hline Type of traumatic lesion & & & & \\
\hline $\mathrm{VI}$ & $13(76.5)$ & $4(23.5)$ & $150(30.6$ to 856$)$ & $<0.001 \dagger$ \\
\hline $\mathrm{V}$ & 43 (18.2) & $193(81.8)$ & 10.3 (3.81 to 30.2 ) & $<0.001$ \\
\hline IV & $12(50.0)$ & $12(50.0)$ & 46.2 (12.4 to 184$)$ & $<0.001 \dagger$ \\
\hline III & $41(29.5)$ & $98(70.5)$ & $19.3(7.04$ to 57.5$)$ & $<0.001$ \\
\hline$\|^{*}$ & $5(2.3)$ & $210(97.7)$ & 1 & - \\
\hline $\mathrm{I}^{*}$ & $0(0)$ & $21(100)$ & 1 & - \\
\hline Epidural haematoma & & & & \\
\hline Yes & $5(5.7)$ & $83(94.3)$ & 0.25 (0.09 to 0.66$)$ & 0.002 \\
\hline $\mathrm{No}^{*}$ & $109(19.3)$ & $455(80.7)$ & 1 & - \\
\hline Subdural haematoma & & & & \\
\hline Yes & $66(27.2)$ & $177(72.8)$ & 2.80 (1.82 to 4.33$)$ & $<0.001$ \\
\hline No* & 48 (11.7) & $361(88.3)$ & 1 & - \\
\hline Focal brain contusion & & & & \\
\hline Yes & $17(11.8)$ & $127(88.2)$ & $0.57(0.31$ to 1.01$)$ & 0.04 \\
\hline $\mathrm{No}^{*}$ & $97(19.1)$ & $411(80.9)$ & 1 & - \\
\hline SAH & & & & \\
\hline Yes & $46(38.3)$ & $74(61.7)$ & $4.24(2.65$ to 6.80$)$ & $<0.001$ \\
\hline $\mathrm{No}^{*}$ & 68 (12.8) & $464(87.2)$ & 1 & - \\
\hline IVH & & & & \\
\hline Yes & $54(27.7)$ & $141(72.3)$ & 2.53 (1.64 to 3.92 ) & $<0.001$ \\
\hline $\mathrm{No}^{*}$ & $60(13.1)$ & $397(86.9)$ & 1 & - \\
\hline Brain swelling & & & & \\
\hline Yes & $109(27.2)$ & $292(72.8)$ & $18.4(7.09$ to 51.9$)$ & $<0.001$ \\
\hline $\mathrm{No}^{*}$ & $5(2.0)$ & $246(98.0)$ & & - \\
\hline
\end{tabular}




\begin{tabular}{|c|c|c|c|c|}
\hline \multirow[b]{2}{*}{ Variable } & \multicolumn{2}{|c|}{ No $(\%)$ of patients $(n=652)$} & \multirow[b]{2}{*}{ OR $(95 \% \mathrm{Cl})$} & \multirow[b]{2}{*}{ p Value } \\
\hline & $\begin{array}{l}\text { Dead within } \\
\text { the first } 48 \mathrm{~h} \\
\text { ( } \mathrm{h}=114)\end{array}$ & $\begin{array}{l}\text { Remaining } \\
\text { patients } \\
(\mathrm{n}=538)\end{array}$ & & \\
\hline \multicolumn{5}{|c|}{ Cerebral ischaemia } \\
\hline Yes & $109(27.2)$ & $292(72.8)$ & 18.4 (7.09 to 51.9$)$ & $<0.001$ \\
\hline Yes & $26(59.1)$ & $18(40.9)$ & 8.54 (4.30 to 17.0$)$ & $<0.001$ \\
\hline \multicolumn{5}{|c|}{ Basal cisterns compressed } \\
\hline Yes & $109(27.2)$ & $292(72.8)$ & 18.4 (7.09 to 51.9$)$ & $<0.001$ \\
\hline $\mathrm{No}^{*}$ & $5(2.0)$ & $246(98.0)$ & 1 & - \\
\hline \multicolumn{5}{|c|}{ Midline shift } \\
\hline Yes & $57(30.2)$ & $132(69.8)$ & 3.08 (1.99 to 4.76 ) & $<0.001$ \\
\hline $\mathrm{No}^{*}$ & 57 (12.3) & $406(87.7)$ & 1 & - \\
\hline \multicolumn{5}{|c|}{ Lesion volume $>25 \mathrm{ml}$} \\
\hline Yes & $42(30.2)$ & $97(69.8)$ & 2.65 (1.67 to 4.21$)$ & $<0.001$ \\
\hline $\mathrm{No}^{*}$ & $72(14.0)$ & $441(86.0)$ & 1 & - \\
\hline \multicolumn{5}{|c|}{$\begin{array}{l}\text { GCS, Glasgow Coma Scale; IVH, intraventricular haemorrhage; SAH, subarachnoid haemorrhage; -, data no } \\
\text { applicable. } \\
\text { *Reference categories. } \\
\text { tFisher's exact test. }\end{array}$} \\
\hline
\end{tabular}

Final outcome was considered as the dependent variable and dichotomised into patients who died within the first $48 \mathrm{~h}$ of injury (early death) versus the remainder. This latter group was graded at 6 months after injury according to the Glasgow Outcome Scale ${ }^{6}$ categories: good recovery, moderate disability, severe disability, vegetative state and death.

\section{Data analysis}

The information provided by all the independent variables of the study was collected during the first $6 \mathrm{~h}$ after trauma. The results of the descriptive analysis were compared between both cohorts. Overall and early-death rates in the total sample as well as in both sets were also calculated.

In the derivation cohort, we identified those variables significantly associated with early death (first $48 \mathrm{~h}$ of injury). The $\chi^{2}$ test, with Yates correction when indicated, and Fisher's exact test were used to compare categorical qualitative variables. Student's t test was used for comparison of continuous qualitative and quantitative variables. The association between variables was considered to be significant when the probability $(\mathrm{p})$ value was $<0.05$.

Using the logistic regression method, we identified the independent prognostic factors of early death, applying a selection of variables "directed" so that the different indicators were tested until we found the set (prognostic model) that worked better. The risk was quantified using odds ratios (ORs) with 95\% confidence intervals (CIs) for every prognostic factor. After identifying independent predictors, points were assigned to each prognostic factor by dividing the coefficient of each predictor (from the logistic regression analysis) by the smallest coefficient, and then rounding each quotient to the nearest integer.

Reliability, the concordance between predicted and observed outcomes, was analysed by groups of patients depending on their predicted risk and comparing the observed prevalence of the outcome in each group with the expected value. The goodness of fit of the logistic regression model was tested by the Hosmer-Lemeshow test in both cohorts. Receiver-operator characteristic (ROC) curves were constructed by a series of cut-off points from both the derivation and validation sets. Both curves were analysed by calculating the area under ROC curves and the 95\% CI to establish whether model prediction was better than chance prediction. Discrimination, the ability to separate patients with and without the outcome of interest, was compared using the distribution of predictions for patients with and without the outcome of intent (early death $v$ remainder).
Finally, we calculated a prediction score to estimate the likelihood of early death for each patient by summing the total number of points. Sensitivity, specificity, positive and negative predictive values, and overall accuracy of each score were also determined.

Statistical analyses were carried out using the SAS system statistical package.

\section{RESULTS}

A comparison between both cohorts was carried out without finding important differences, although early mortality was considerably greater in the validation set (data not shown). On the other hand, the overall mortality in this series was $46.8 \%$ (419 of the 895 patients, 314 in the derivation cohort and 105 in the validation cohort). Of these patients, $42.2 \%$ died within the first $48 \mathrm{~h}$ of injury ( 177 of 419,114 in the derivation set and 63 in the validation set), yielding an earlydeath rate of $19.8 \%$ (177 of the 895 patients) (data not shown).

\section{Univariate analysis for patients in the derivation set}

Table 1 summarises the results of univariate analysis for patients in the derivation cohort. The variables markedly associated with early death (first $48 \mathrm{~h}$ ) were: age $\geqslant 65$ years; total GCS scores of 3, 4 or 5, and low total GCS score; motor GCS scores of 1, 2 or 3, and low motor GCS score; nonreactive bilateral mydriasis and non-reactive unilateral mydriasis; shock; hypoxia; urgent extracranial surgery; anaemia; coagulopathy; traumatic lesion types VI, IV, III and V; subdural haematoma; subarachnoid haemorrhage; intraventricular haemorrhage; brain swelling; cerebral ischaemia; basal cisterns compressed (numbers equal to those of brain swelling); midline shift and lesion volume $>25 \mathrm{ml}$. In contrast, other variables were strongly "protective" with respect to early death: seizure $(p=0.02)$; epidural haematoma $(p=0.002)$ and focal brain contusion ( $p=0.04$; marginally significant). The remaining variables did not show significant association with early death, and for that reason they are not shown in table 1 .

\section{Multivariate analysis}

Multivariate analysis identified the independent prognostic factors of early death, assigning in addition a score to each of them depending on their logistic regression coefficients (table 2). Theoretically, the total score for each patient would range from 0 to 10 . However, no patient of our study scored 10 points. 


\begin{tabular}{|c|c|c|c|c|c|}
\hline Variable & Coefficient & $\begin{array}{l}\text { Standard } \\
\text { error }\end{array}$ & OR $(95 \% \mathrm{Cl})$ & p Value & Points* \\
\hline Age (years $\geqslant 65$ ) & 1.29 & 0.48 & $3.62(1.42$ to 9.23$)$ & 0.007 & 1 \\
\hline Flaccidity & 1.94 & 0.40 & 6.93 (3.15 to 15.3 ) & $<0.001$ & 2 \\
\hline Decerebration & 1.24 & 0.37 & 3.44 (1.65 to 7.17$)$ & 0.001 & 1 \\
\hline $\begin{array}{l}\text { Non-reactive bilateral } \\
\text { mydriasis }\end{array}$ & 1.85 & 0.34 & 6.33 (3.25 to 12.3 ) & $<0.001$ & 2 \\
\hline Shock & 1.18 & 0.32 & $3.27(1.76$ to 6.07$)$ & $<0.001$ & 1 \\
\hline Traumatic lesion type III & 2.03 & 0.55 & $7.64(2.61$ to 22.4$)$ & $<0.001$ & 2 \\
\hline Traumatic lesion type IV & 3.20 & 0.77 & 24.5 (5.36 to 112$)$ & $<0.001$ & 3 \\
\hline Traumatic lesion type V & 1.37 & 0.54 & $3.92(1.37$ to 11.2$)$ & 0.01 & 1 \\
\hline Traumatic lesion type VI & 4.17 & 0.90 & $64.6(11.0$ to 379$)$ & $<0.001$ & 4 \\
\hline
\end{tabular}

*Each coefficient was divided by 1.18 and the quotient rounded to the nearest integer to determine the number of points assigned to that independent predictor.

The prognostic model worked correctly when it was applied to the validation cohort. Thus, the predicted outcomes were compared with observed ones in groups of patients according to their predicted risk, obtaining similar values (derivation: $\mathrm{p}=0.27, \mathrm{df}=6$; validation: $\mathrm{p}=0.98, \mathrm{df}=7$; HosmerLemeshow test). The areas under the ROC curves for the derivation set and the validation set were 0.93 (95\% CI 0.90 to 0.95 ) and 0.94 (95\% CI 0.90 to 0.97 ), respectively, without significant differences between them $(\mathrm{p}=0.66$; fig 1$)$.

For the 895 patients in the study, we calculated the likelihood of early death for each score (table 3). Taking as reference the scores of 0 and 1 , the risk of early death progressively increases as the score increases. All patients who had 9 points died within the first 48 h of injury. Patients with 7 or 8 points who did not die during the first 48 h ( 4 patients in total) eventually died, between the 3rd and 22nd days after injury. Of the patients who scored 6 points, only one survived, remaining severely disabled. Similarly, four patients who scored 5 points survived, two of them severely disabled and the other two moderately disabled.

In table 4 , the sensitivity, specificity, positive predictive value, negative predictive value and the percentage of patients correctly classified are shown for each score or cutoff point in the 895 patients in the study. One of the most

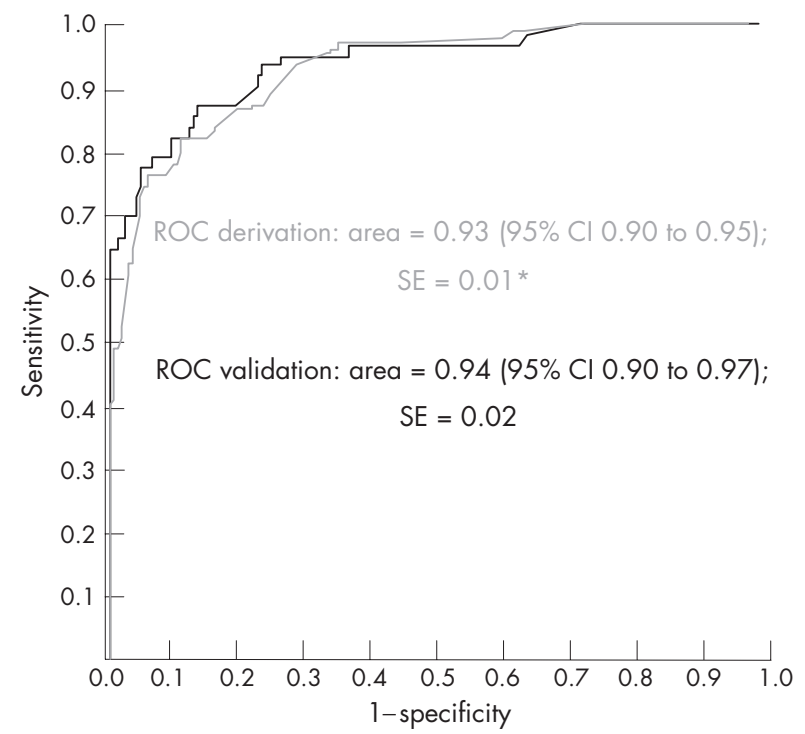

Figure 1 Receiver-operator characteristic (ROC) curves of the bedside scoring system using independent prognostic factors of early death after severe head injury: comparison between derivation set and validation set. $\mathrm{Cl}$, confidence interval; $\mathrm{SE}$, standard error. interesting matters rests on calculating the error of the model-in particular when it predicts that patients will survive after the first $48 \mathrm{~h}$ of trauma but in fact they die within this time (false-negative rate). If we do not apply any selection criterion, we will have all patients available but we have to assume an early-death rate of $19.8 \%$. From another point of view, if the aim rests on accepting, for instance, an early-death rate of $4.6 \%$, it will be necessary to exclude $26.6 \%$ of the patients.

\section{DISCUSSION}

The final outcome regarding SHI is determined by the effect of prognostic factors, the treatment effect and the random effect. To reduce the random effect, different "prognostic models" have been carried out since the mid-70s, with the main objective of performing reliable predictions for future patients with SHI. ${ }^{7-17}$ Up-to-date studies related to prediction for SHI have concluded that accurate prediction of outcome is impossible through the first $6 \mathrm{~h}$ of injury. ${ }^{18}{ }^{19}$ On the other hand, several reports ${ }^{20}{ }^{21}$ suggest that accuracy of predictions based on late assessments is greater when only two outcomes (death or survival) are considered; so the likelihood of death or SD state can usually be predicted accurately after the first $24 \mathrm{~h}$ of SHI. Therefore, it could be useful that these models estimate only the likelihood of death, identifying only that group of patients with high probability of dying.

In the past "decade of the brain", several neuroprotective agents have been tested in phase III clinical trials for SHI, but unfortunately the results have been disappointing. ${ }^{122} 23$ Possibly, most of the clinical trials carried out till now have lacked a suitable sample size and perhaps they have not been well designed. ${ }^{24}{ }^{25}$ Two schools exist within the statistical community: the "lumpers", who argue that problems resulting from heterogeneity may be obviated in large megatrials, and the "dividers", who would prefer more targeted approaches-that is, clinical trials focused on patients with an "intermediate" risk. ${ }^{125-27}$ To focus on this population with an "intermediate" risk, it would be necessary, at first, not to include in these clinical trials patients with high likelihood of dying, as they could dilute the potential benefit of the drug. Thus, we would try to design phase III studies "custom made" for the specific population to be studied..$^{22}$

The overall mortality in our series was higher than that reported by others, a difference probably due to the inclusion of more severely injured patients in our study secondary to the aggressive measures of resuscitation used in our hospital to obtain the greatest number of potential organ donors. Given that the prognostic models are better correlated with mortality than with the overall prognosis, and as most patients with SHI die during the first days after 
Table 3 Probability of early death depending on the observed score

\begin{tabular}{lllll}
\hline $\begin{array}{l}\text { Prediction } \\
\text { score }\end{array}$ & $\begin{array}{l}\text { Early deaths, } \\
\text { No/no of patients }\end{array}$ & $\begin{array}{l}\text { Early-death } \\
\text { rate }(\%)\end{array}$ & OR $(95 \%$ CI) & p Value \\
\hline $0^{*}$ & $0 / 186$ & 0 & & \\
$1^{*}$ & $5 / 208$ & 2.4 & 1 & $<0.001 \dagger$ \\
2 & $12 / 164$ & 7.3 & $6.14(1.97$ to 20.4$)$ & $<0.001 \dagger$ \\
3 & $13 / 99$ & 13.1 & $11.8(3.78$ to 38.9$)$ & $<0.001 \dagger$ \\
4 & $16 / 67$ & 23.9 & $24.4(7.94$ to 80.0$)$ & $<0.001 \dagger$ \\
5 & $31 / 60$ & 51.7 & $83.2(28.0$ to 265$)$ & $<0.001 \dagger$ \\
6 & $27 / 34$ & 79.4 & $300(79.1$ to 1261$)$ & $<0.001$ \\
7 & $46 / 49$ & 93.9 & $1193(239$ to 7277$)$ & \\
8 & $20 / 21$ & 95.2 & $1556(159$ to 38114$)$ & $<0.001 \dagger$ \\
9 & $7 / 7$ & 100 & - & \\
\hline
\end{tabular}

\begin{tabular}{|c|c|c|c|c|c|c|}
\hline $\begin{array}{l}\text { Prediction } \\
\text { score }\end{array}$ & $\begin{array}{l}\text { No }(\%) \text { of } \\
\text { patients }\end{array}$ & $\begin{array}{l}\text { Sensitivity } \\
\text { (\%) }\end{array}$ & $\begin{array}{l}\text { Specificity } \\
(\%)\end{array}$ & PPV (\%) & NPV (\%) & $\begin{array}{l}\text { Patients correctly } \\
\text { classified (\%) }\end{array}$ \\
\hline$\geqslant 0$ & $895(100)$ & 100 & - & 19.8 & - & 19.8 \\
\hline$\geqslant 1$ & 709 (79.2) & 100 & 25.9 & 25.0 & 100 & 40.6 \\
\hline$\geqslant 2$ & $501(56.0)$ & 97.2 & 54.2 & 34.3 & 98.7 & 62.7 \\
\hline$\geqslant 3$ & $337(37.7)$ & 90.4 & 75.3 & 47.5 & 97.0 & 78.3 \\
\hline$\geqslant 4$ & $238(26.6)$ & 83.1 & 87.3 & 61.8 & 95.4 & 86.5 \\
\hline$\geqslant 5$ & $171(19.1)$ & 74.0 & 94.4 & 76.6 & 93.6 & 90.4 \\
\hline$\geqslant 6$ & 111 (12.4) & 56.5 & 98.5 & 90.1 & 90.2 & 90.2 \\
\hline$\geqslant 7$ & $77(8.6)$ & 41.2 & 99.4 & 94.8 & 87.3 & 87.9 \\
\hline$\geqslant 8$ & $28(3.1)$ & 15.3 & 99.9 & 96.4 & 82.7 & 83.1 \\
\hline$\geqslant 9$ & $7(0.8)$ & 4.0 & 100 & 100 & 80.9 & 81.0 \\
\hline$\geqslant 10$ & $0(0)$ & - & 100 & - & 80.2 & 80.2 \\
\hline
\end{tabular}

PPV, positive predictive value; NPV, negative predictive value. -, data not applicable.

trauma, ${ }^{13} 142829$ we decided to develop a simple prognostic model with an alternative final objective: the probability of early death after SHI. ${ }^{30}$ We defined early mortality as death that occurs within the first $48 \mathrm{~h}$ of injury, ${ }^{31}$ after observing the death of patients in our study, almost half of whom died in that time. These patients died due to the severity of their injuries and, as a whole, they represented about $20 \%$ of all patients in our series. In this context, not many studies that specifically contemplate the aspect of early death in SHI have been carried out, and as far as we know, a prognostic model with the characteristics and purposes similar to ours has not been published..$^{32-35}$

Another feature of our model is the possibility of making accurate predictions about mortality within $6 \mathrm{~h}$ after SHI, in contrast with the prognostic models developed to date. The fact that patients in our study were in a coma for the first $6 \mathrm{~h}$ and it was possible to carry out a computed tomography scan in that time defines a minimum and a maximum level of severity, thus making the group that we studied well defined and relatively homogeneous. ${ }^{12}$ Another reason to choose the interval of $6 \mathrm{~h}$ was that many of the trials carried out for SHI to date have generally used a therapeutic window of at least $8 \mathrm{~h}$ after trauma. ${ }^{1}$

The patients included in clinical trials for SHI are heterogeneous. ${ }^{30}$ In these trials, the contingency that, for instance, patients have had episodes of shock or hypoxia (even cardiorespiratory arrest) before their inclusion is not considered. Similarly, it is not considered that their neurological states deteriorate through the first hours of injury or that their lesions seen on computed tomography scan change. Thus, we can state that some patients with SHI have greater likelihood of early death, as their outcomes strictly depend on the severity of the initial injury and, therefore, are hardly modifiable. ${ }^{5}{ }^{23} 26^{36-38} \mathrm{In}$ fact, it is noteworthy that the only "avoidable" variable of our model is shock. The prediction score system developed from our study is simple to apply, as it only requires a correct neurological examination and a computed tomography scan during the first $6 \mathrm{~h}$ after injury, and thus can be used in any hospital without neurosurgical infrastructure. From this scoring system, it is possible to have a more precise idea of the real severity of these patients. Moreover, our prognostic model would rule out the greatest number of patients who are going to die within the first $48 \mathrm{~h}$ after injury, without losing an important number of people potentially suitable for inclusion in the clinical trials. Thus, it is possible to achieve inclusion of more homogeneous patients in these trials, optimisation of the type and number of people entered and, consequently, reduction in the costs. Although one potential drawback of more extreme targeting of trial participants is that it would limit the generalisability of the findings, perceived particularly as a problem by the pharmaceutical companies, this strategy has been found to allow a reduction in sample size by $30 \%$ for the same statistical power. ${ }^{22} 2527$

Another consequence of our work rests in advocating extraordinary therapeutic measures in these patients who are going to die precociously, but managing them as potential organ donors. ${ }^{14} 3339$ Considering the ethical and legal connotations that a strategy of this type entails, ${ }^{20}$ more databases and of sizes greater than that of ours are required to carry out absolutely reliable predictions on this matter.

Finally, it is important to remember that a very sensitive and specific model will be a poor predictor in a population in which the outcome is rare, or simply different from that observed in the model population. ${ }^{90}$ For this reason, the generalisation of our model requires caution for the moment, as it has not been prospectively validated in a setting different from that of our hospital. 


\section{ACKNOWLEDGEMENTS}

This study was supported by Mutua Madrileña Foundation.

\section{Authors' affiliations}

G R Boto, P A Gómez, R D Lobato, Department of Neurosurgery, Hospital 12 de Octubre, Madrid, Spain

J D L Cruz, Unit of Epidemiology, Hospital 12 de Octubre

Competing innterests: None declared.

\section{REFERENCES}

1 Narayan RK, Michel ME, Ansell B, et al. Clinical trials in head injury. J Neurotrauma 2002;19:503-57.

2 Teasdale G, Jennett B. Assessment of coma and impaired consciousness. A practical scale. Lancet 1974;2:81-4.

3 Morris GF, Juul N, Marshall SB, et al. Neurological deterioration as a potential alternative endpoint in human clinical trials of experimental pharmacological agents for treatment of severe traumatic brain injuries. Executive Committee of the International Selfotel Trial. Neurosurgery 1998:43:1369-74

4 Marshall LF, Marshall SB, Klauber MR, et al. A new classification of head injury based on computerized tomography. I Neurosurg $1991 ; 75$ (Suppl):S14-20.

5 Lobato RD, Gomez PA, Alday R, et al. Sequential computerized tomography changes and related final outcome in severe head injury patients. Acta Neurochir (Wien) 1997;139:385-91.

6 Jennett B, Bond M. Assessment of outcome after severe brain damage. Lancet 1975;1:480-4

7 Choi SC, Barnes TY. Predicting outcome in the head-injured patient. In: Narayan RK, Willberger JE, Povlishock JT, eds. Neurotrauma. New York: McGraw-Hill, 1996:779-92.

8 Choi SC, Narayan RK, Anderson RL, et al. Enhanced specificity of prognosis in severe head injury. I' Neurosurg 1988;69:381-85.

9 Contant CF Jr, Narayan RK. Prognosis after head injury. In: Youmans JR, eds. Neurological surgery. 4th edn. Philadelphia: WB Saunders, 1996:1792-812.

10 Giannotta SL, Weiner JM, Karnaze D. Prognosis and outcome in severe head injury. In: Cooper PR, eds. Head injury. 2nd edn. Baltimore: Williams \& Wilkins, 1987:464-87.

11 Mamelak AN, Pitts LH, Damron S. Predicting survival from head trauma 24 hours after injury: a practical method with therapeutic implications. J Trauma 1996;41:91-9.

12 Murray GD, Murray LS, Barlow P, et al. Assessing the performance and clinical impact of a computerized prognostic system in severe head injury. Stat Med 1986;5:403-10

13 Vollmer DG. Prognosis and outcome of severe head injury. In: Cooper PR, eds. Head injury. 3rd edn. Baltimore: Williams \& Wilkins, 1993:553-81.

14 Feldman Z. The limits of salvageability in head injury. In: Narayan RK Willberger JE, Povlishock JT, eds. Neurotrauma. New York: McGraw-Hill, 1996:805-17.

15 Jennett B, Teasdale G, Knill-Jones R. Prognosis after severe head injury. Ciba Found Symp 1975:34:309-24.

16 Marshall LF. The role of aggressive therapy for head injury: does it matter? Clin Neurosurg 1988;34:549-59.

17 Murray LS, Teasdale GM, Murray GD, et al. Does prediction of outcome alter patient management? Lancet 1993;341:1487-91.
18 Kaufmann MA, Buchmann B, Scheidegger D, et al. Severe head injury: should expected outcome influence resuscitation and first-day decisions? Resuscitation 1992;23:199-206.

19 Waxman K, Sundine M, Young RF. Is early prediction of outcome in severe head injury possible? Arch Surg 1991;126:1237-42.

20 Feldman Z, Contant CF, Robertson CS, et al. Evaluation of the Leeds prognostic score for severe head injury. Lancet 1991;337:1451-53.

21 Lang EW, Pitts LH, Damron SL, et al. Outcome affer severe head injury: an analysis of prediction based upon comparison of neural network versus logistic regression analysis. Neurol Res 1997;19:274-80.

22 Bullock MR, Lyeth BG, Muizelaar JP. Current status of neuroprotection trials for traumatic brain injury: lessons from animal models and clinical studies. Neurosurgery 1999;45:207-20.

23 Maas Al, Steyerberg EW, Murray GD, et al. Why have recent trials of neuroprotective agents in head injury failed to show convincing efficacy? A pragmatic analysis and theoretical considerations. Neurosurgery 1999;44:1286-98.

24 Dickinson K, Bunn F, Wentz R, et al. Size and quality of randomised controlled trials in head injury: review of published studies. BMJ 2000;320:1308-11.

25 Hukkelhoven CW, Steyerberg EW, Maas Al. Quality of randomised controlled trials in head injury. Statistical power can be increased [letter]. BMJ 2000;321:704.

26 Imberti $\mathbf{R}$. Why have recent trials of neuroprotective agents in head injury failed to show [letter]. Neurosurgery 2003;53:241-2.

27 Machado SG, Murray GD, Teasdale GM. Evaluation of designs for clinical trials of neuroprotective agents in head injury. European Brain Injury Consortium. J Neurotrauma 1999;16:1131-8.

28 Conroy C, Kraus JF. Survival after brain injury. Cause of death, length of survival, and prognostic variables in a cohort of brain-injured people. Neuroepidemiology 1988;7:13-22.

29 Sekulovic N, Ceramilac A. Brain injuries-causes of death and life expectancy. Acta Neurochir (Wien) 1979;28(Suppl):203-4.

30 Marshall LF, Maas Al, Marshall SB, et al. A multicenter trial on the efficacy of using tirilazad mesylate in cases of head injury. I Neurosurg 1998;89:519-25

31 Clifton GL, McCormick WF, Grossman RG. Neuropathology of early and late deaths after head injury. Neurosurgery 1981:8:309-14.

32 Combes P, Fauvage B, Colonna M, et al. Severe head injuries: an outcome prediction and survival analysis. Intensive Care Med 1996;22:1391-5.

33 Gibson RM, Stephenson GC. Aggressive management of severe closed head trauma: time for reappraisal. Lancet 1989:2:369-71.

34 Schreiber MA, Aoki N, Scott BG, et al. Determinants of mortality in patients with severe blunt head injury. Arch Surg 2002;137:285-90.

35 Signorini DF, Andrews PJ, Jones PA, et al. Predicting survival using simple clinical variables: a case study in traumatic brain injury. I Neurol Neurosurg Psychiatry 1999:66:20-5.

36 Yamaki T, Murakami N, Iwamoto Y, et al. Pathological study of diffuse axonal injury patients who died shortly after impact. Acta Neurochir (Wien) 1992;119:153-8.

37 Oertel M, Kelly DF, McArthur D, et al. Progressive hemorrhage after head trauma: predictors and consequences of the evolving injury. J Neurosurg 2002;96:109-16.

38 Servadei F, Murray GD, Penny K, et al. The value of the "worst" computed tomographic scan in clinical studies of moderate and severe head injury. European Brain Injury Consortium. Neurosurgery 2000:46:70-7.

39 Dickerson J, Valadka AB, Levert T, et al. Organ donation rates in a neurosurgical intensive care unit. J Neurosurg 2002;97:811-14.

40 Hukkelhoven CW, Steyerberg EW, Farace E, et al. Regional differences in patient characteristics, case management, and outcomes in traumatic brain injury: experience from the tirilazad trials. J Neurosurg 2002;97:549-57. 